\title{
Benchmark of Subchannel Code VIPRE-W with PSBT Void and Temperature Test Data
}

\author{
Y. Sung, ${ }^{1}$ R. L. Oelrich Jr., ${ }^{1}$ C. C. Lee, ${ }^{1}$ N. Ruiz-Esquide, ${ }^{2}$ M. Gambetta, ${ }^{2}$ and C. M. Mazufri ${ }^{2}$ \\ ${ }^{1}$ Westinghouse Nuclear Fuel Business Unit, 1000 Westinghouse Drive, Suite 452, Cranberry Township, PA 16066, USA \\ ${ }^{2}$ INVAP Nuclear Engineering Department, Avenida Comandante Luis Piedrabuena 4950 San Carlos de Bariloche, \\ R8403CPV Rio Negro, Argentina
}

Correspondence should be addressed to Y. Sung, sungy@westinghouse.com

Received 23 March 2012; Accepted 1 July 2012

Academic Editor: Maria Avramova

Copyright (C 2012 Y. Sung et al. This is an open access article distributed under the Creative Commons Attribution License, which permits unrestricted use, distribution, and reproduction in any medium, provided the original work is properly cited.

\begin{abstract}
This paper summarizes comparisons of VIPRE-W thermal-hydraulic subchannel code predictions with measurements of fluid temperature and void from pressurized water reactor subchannel and bundle tests. Using an existing turbulent mixing model, the empirical coefficient derived from code predictions in comparison to the fluid temperature measurement is similar to those from previous mixing tests of similar bundle configurations. The predicted steady-state axial void distributions and time-dependent void profiles based on the Lellouche and Zolotar model generally agree well with the test data. The void model tends to predict lower void at the upper elevation under bulk boiling. The void predictions are in closer agreement with the measurements from the power increase, temperature increase, and flow reduction transients than the depressurization transient. Additional model sensitivity studies showed no significant improvement in the code predictions as compared to the published test data.
\end{abstract}

\section{Introduction}

VIPRE-W (VIPREW or VIPRE) is Westinghouse version of the VIPRE-01 (VIPRE-01 is owned by the Electric Power Research Institute, Palo Alto, CA, USA) thermal-hydraulic subchannel code developed for light water reactor core design applications. The Penn State University (PSU), in cooperation with the Japan Nuclear Energy Safety Organization (JNES), under the sponsorship of the Organization for Economic Co-Operation and Development (OECD) and the United States Nuclear Regulatory Commission (USNRC), has developed benchmark exercises based on the Nuclear Power Engineering Corporation (NUPEC) pressurized water reactor (PWR) subchannel and bundle tests (PSBTs) [1]. The benchmark exercises include Phase I/Exercise 2 for the steady-state void distributions, Phase I/Exercise 3 for the transient void distributions, and Phase II/Exercise 1 for the steady-state fluid temperature distributions in the $5 \times$ 5 rod bundles under PWR design conditions. This paper summarizes comparisons of VIPRE-W code predictions with the PSBT fluid temperature and void data, as well as sensitivity studies on the VIPRE-W modeling options.

\section{Test Description}

The PSBT problem specifications [1] provide a description of the NUPEC test facility and rod bundle designs. The test bundles were in $5 \times 5$ configurations for the void and exit temperature measurements, simulating a PWR $17 \times$ 17 fuel assembly design with a fuel rod outside diameter (OD) of $9.5 \mathrm{~mm}$ containing simple support and mixing vane (MV) grid spacers. The test section for the rod bundle void distribution measurement and an axial diagram indicating locations of grid spacers and pressure taps are shown in Figure 1. The effective heated length is $3658 \mathrm{~mm}$. Similar to rod bundle tests performed at the former Heat Transfer Research Facility (HTRF) in New York [2]; the test rods were heated electrically using different wall thicknesses in order to create uniform or cosine axial power profiles. For example, the heater rods for the uniform axial power profile were made of Inconel 600 tubes with a wall thickness of $0.65 \mathrm{~mm}$. The tube inside was fit with an insulator tube made of alumina having an OD of $8.2 \mathrm{~mm}$ and an inside diameter (ID) of $5.8 \mathrm{~mm}$. Table 1 describes different test bundles used for the void and exit temperature measurements. For the void 
TABLE 1: Description of PSBT void and mixing tests.

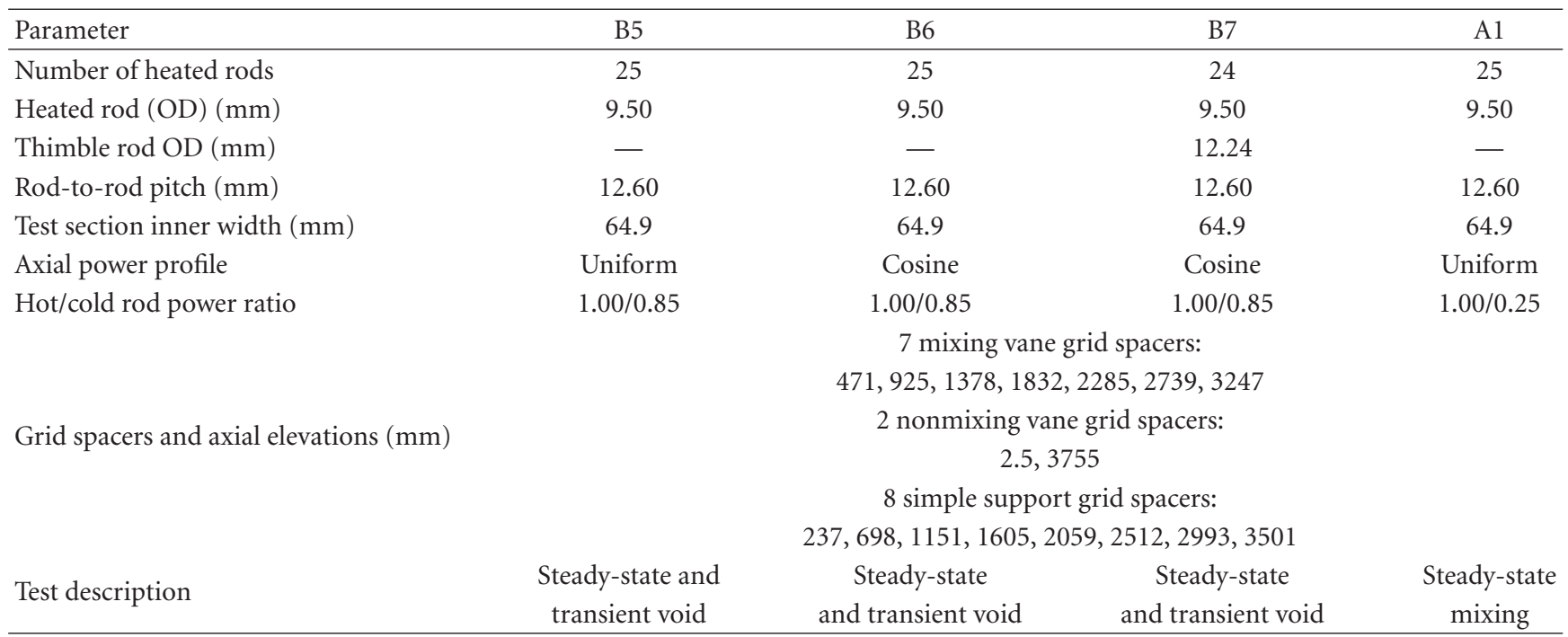

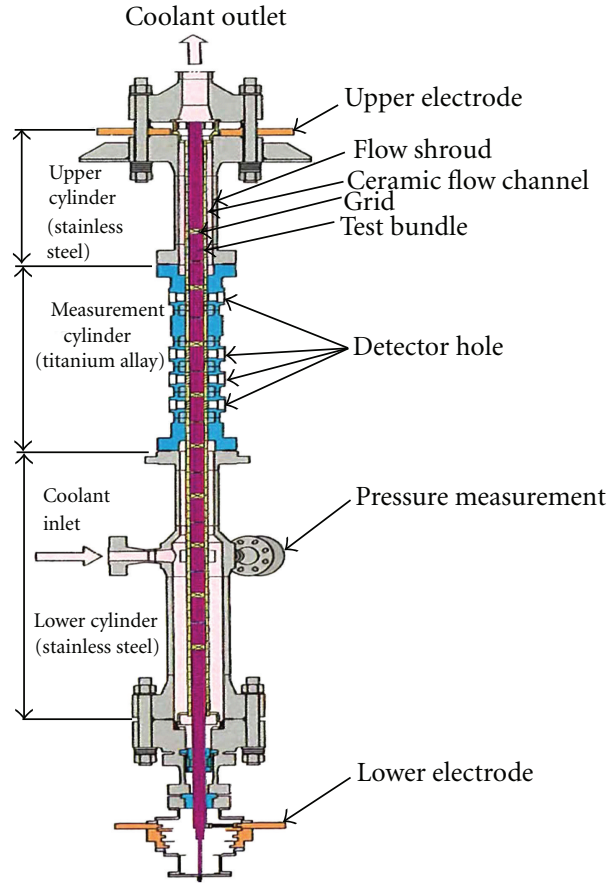

(a)

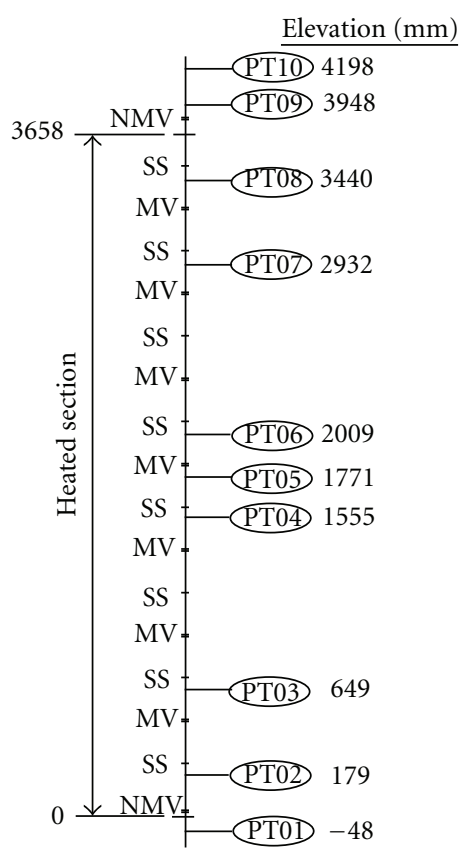

(b)

Figure 1: PSBT test section and axial diagram of test bundles [1].

tests, the inner rods of a test bundle with the higher power were designated as "hot" rods, while the peripheral rods at lower power were "cold" rods. For the mixing test, the cold and hot rods were arranged in two columns on each side of the $5 \times 5$ test bundle, with three cold rods and two hot rods arranged alternatively in the central column. The test data were provided as part of the USNRC/OECD benchmark specifications [1].
2.1. Mixing Test. A fluid temperature test is often referred to as a mixing test, since it was designed to measure turbulent mixing effect in the bundle with a relatively large power gradient between hot and cold rods. In the PSBT mixing test (A1), thirty-six thermocouples were placed at the exit of each subchannel of the $5 \times 5$ test bundle for measuring fluid temperature. A total of 59 experimental data was taken from the test in the range shown in Table 2. 


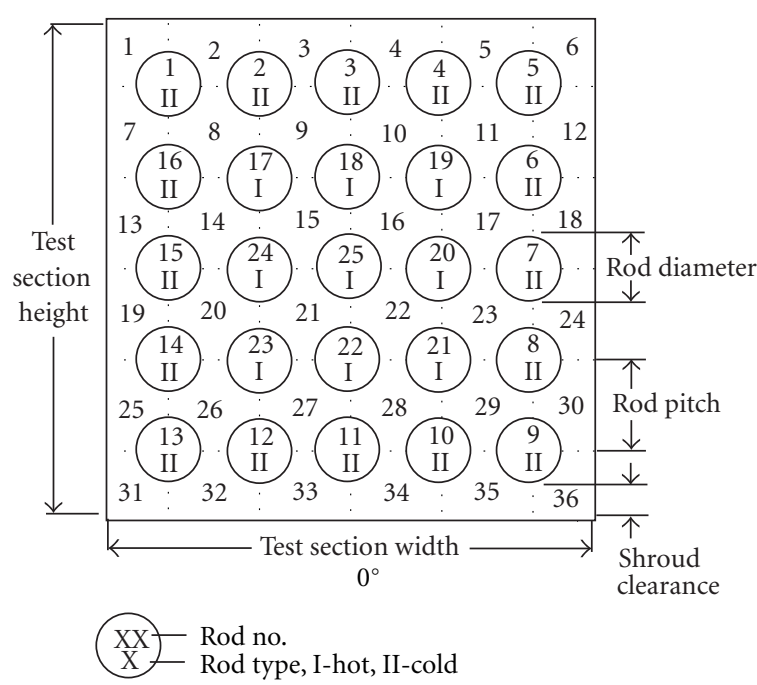

(a)

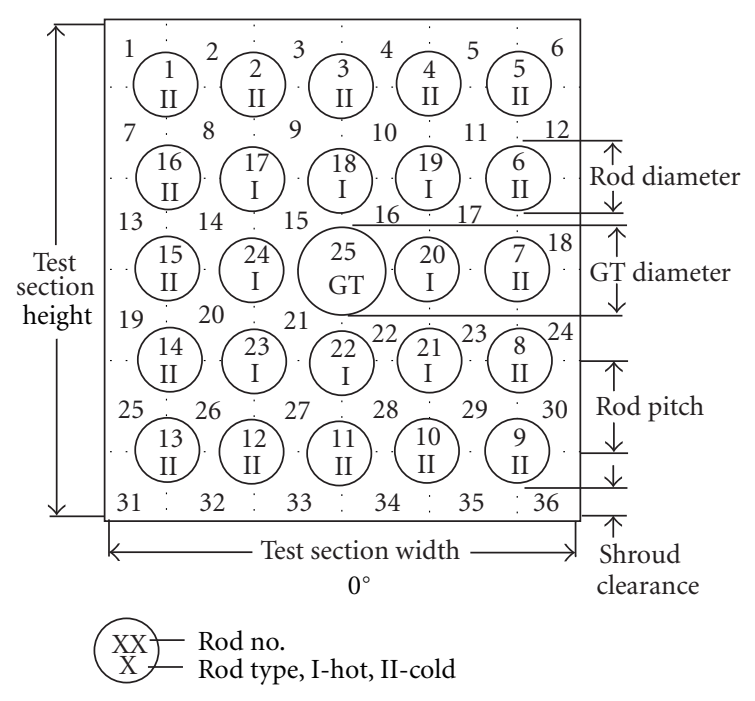

(b)

FIGURE 2: VIPRE-W modeling of PSBT rod bundles.

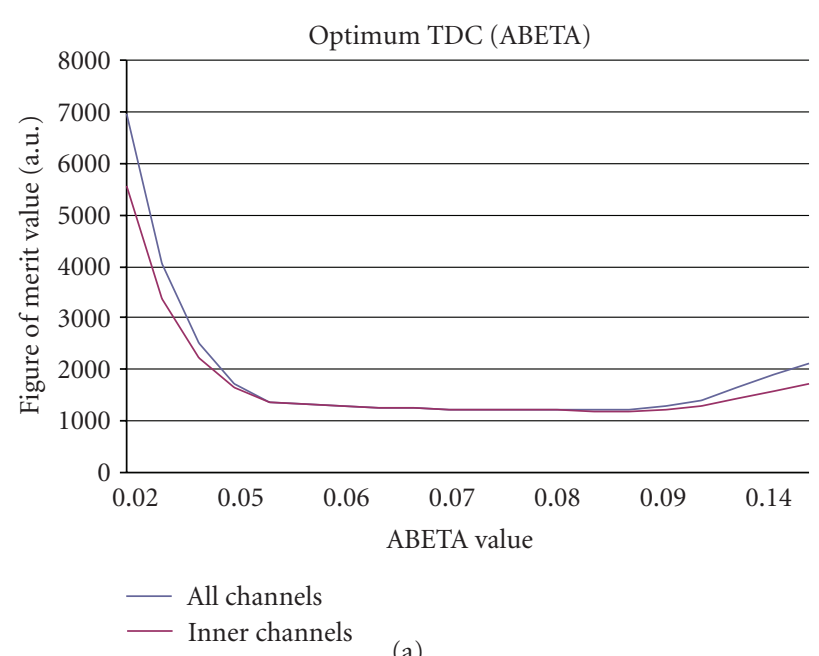

(a)

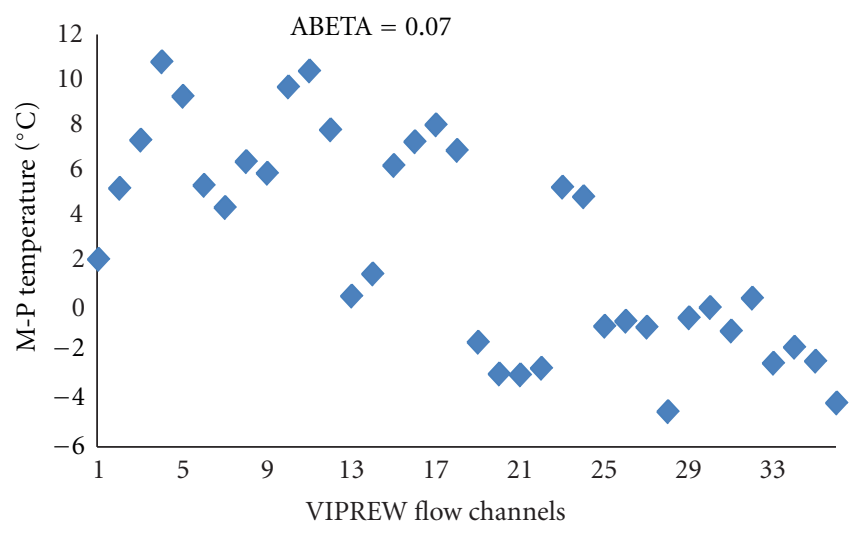

(b)

FIgURE 3: (a) ABETA sensitivity study. (b) Temperature difference versus channels.

TABLE 2: Data range of PSBT mixing test.

\begin{tabular}{lc}
\hline Parameters of mixing test & Range \\
\hline Pressure $($ bar $)$ & $49-166$ \\
Mass flux $\left(10^{6} \mathrm{~kg} / \mathrm{m}^{2} \mathrm{~h}\right)$ & $0.44-17.08$ \\
Inlet temperature $\left({ }^{\circ} \mathrm{C}\right)$ & $84.5-289.2$ \\
Bundle power $(\mathrm{MW})$ & $0.11-3.44$ \\
\hline
\end{tabular}

The mixing test was conducted mainly under the singlephase flow conditions.

2.2. Steady-State Void Tests. The steady-state void tests were performed with three different bundles, B5, B6, and B7, as described in Table 1. Seventy-four void distribution
TABLE 3: Data range of PSBT void tests.

\begin{tabular}{lc}
\hline Parameters of void tests & Range \\
\hline Pressure $($ bar $)$ & $48.0-166$ \\
Mass flux $\left(10^{6} \mathrm{~kg} / \mathrm{m}^{2} \mathrm{~h}\right)$ & $2.0-15.0$ \\
Inlet temperature $\left({ }^{\circ} \mathrm{C}\right)$ & $143-322$ \\
Bundle power $(\mathrm{MW})$ & $0.97-4.0$ \\
Void fraction & $0.0-0.80$ \\
\hline
\end{tabular}

measurements were collected from each bundle in the range shown in Table 3.

A gamma-ray transmission method was used for measuring density of the flow, which was then converted to the void fraction of the vapor-liquid two-phase flow [1]. The measurements were taken at three elevations, $2216 \mathrm{~mm}$ (lower), $2669 \mathrm{~mm}$ (middle), and $3658 \mathrm{~mm}$ (upper). The measured 


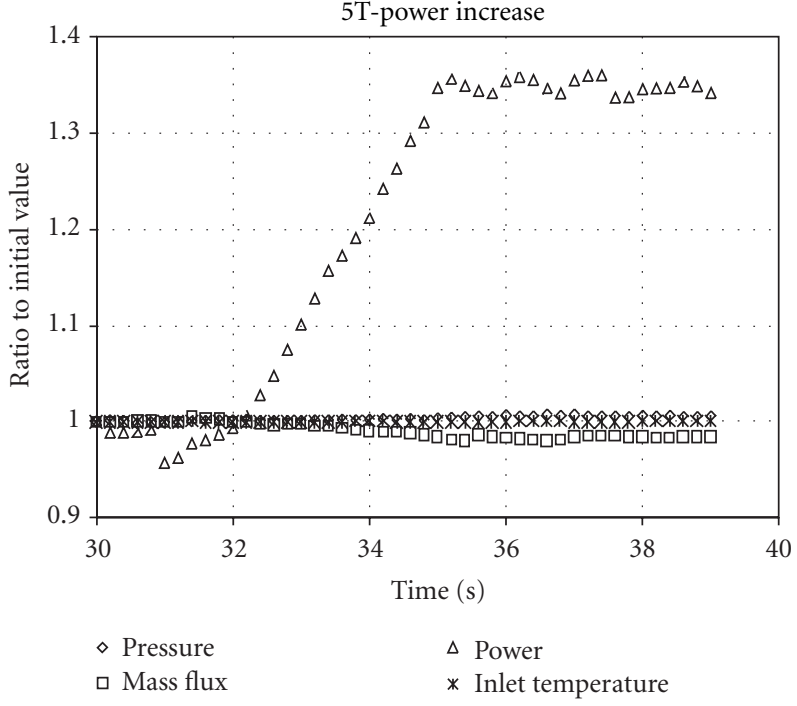

(a)

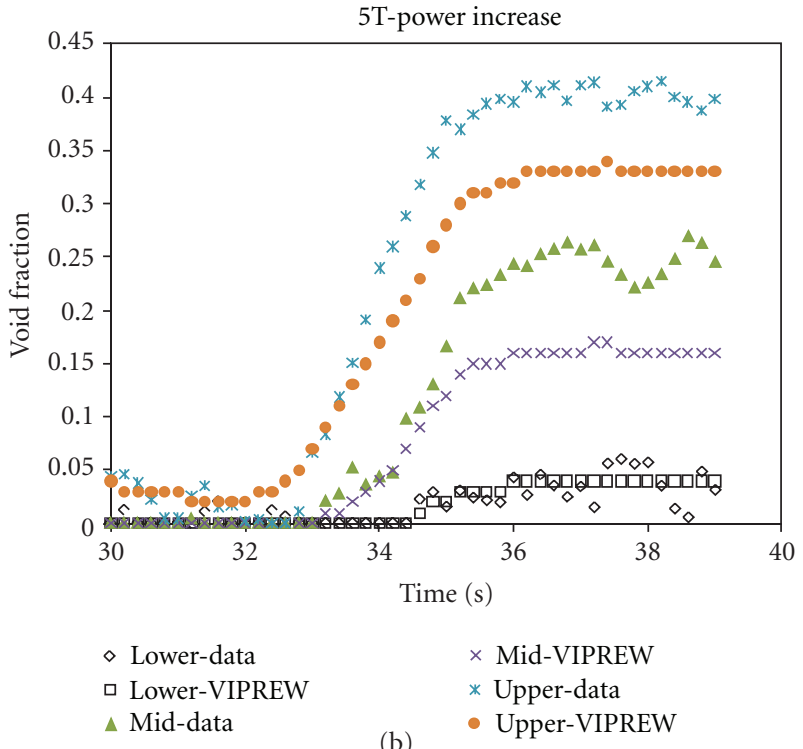

(b)

Figure 4: (a) B5T power increase (PI) transient. (b) B5T PI void comparison.

TABLE 4: Average differences between matched data pairs.

\begin{tabular}{|c|c|c|c|c|c|c|c|}
\hline \multirow[b]{2}{*}{ Parameter $(N=31)$} & \multicolumn{3}{|c|}{ Measured data } & \multicolumn{4}{|c|}{ Testing conditions } \\
\hline & $\begin{array}{c}\Delta \text { Void } \\
\text { (lower) }\end{array}$ & $\begin{array}{c}\Delta \text { Void } \\
\text { (middle) }\end{array}$ & $\begin{array}{c}\Delta \text { Void } \\
\text { (upper) }\end{array}$ & $\begin{array}{c}\Delta \text { Pressure } \\
\text { (bar) }\end{array}$ & $\begin{array}{c}\Delta \text { Flow } \\
\left(10^{6} \mathrm{~kg} / \mathrm{m}^{2} \mathrm{~h}\right)\end{array}$ & $\begin{array}{c}\Delta \text { Temperature } \\
\left({ }^{\circ} \mathrm{C}\right)\end{array}$ & $\begin{array}{l}\Delta \text { Power } \\
(\mathrm{MW})\end{array}$ \\
\hline Mean & 0.011 & 0.062 & 0.022 & 0.516 & 0.035 & -0.528 & 0.007 \\
\hline Standard deviation & 0.030 & 0.049 & 0.026 & 0.629 & 0.071 & 0.367 & 0.014 \\
\hline
\end{tabular}

data were averaged over the four central subchannels of the $5 \times 5$ test bundles.

A repeatability test was performed with another bundle, B8, similar to B5, with the uniform axial power profile and heated rods only (no guide thimble tube). A total of 31 matched pairs having similar test conditions of pressure, flow, inlet temperature and power were identified. The average differences (B8 - B5) in the test conditions and void measurements are given in Table 4 . The matched pairs can be used for evaluating repeatability of the PSBT void test results. There appeared to be larger variations in the void measurements at the middle elevation of the rod bundle than data obtained from either the lower or the upper elevations.

2.3. Transient Void Tests. Transient void tests were performed also with the three bundles, B5, B6, and B7, for four scenarios: power increase, flow reduction, depressurization, and inlet temperature increase. The initial conditions of the transient tests were set to be representative of PWR design conditions shown in Table 5 . The void measurement technique was the same as that used for the steady-state tests. Again, measurements were taken at three elevations, $2216 \mathrm{~mm}$ (lower), $2669 \mathrm{~mm}$ (middle), and $3658 \mathrm{~mm}$ (upper). The measured data were averaged over the four central subchannels of the $5 \times 5$ test bundles.

\section{VIPRE-W Code and Modeling}

VIPRE-W is an enhanced version of the VIPRE-01 subchannel code. VIPRE-01 was developed based on several versions of the COBRA code by the Battelle Pacific Northwest Laboratories for the Electric Power Research Institute (EPRI). It solves the finite difference equations for mass, energy, axial, and lateral momentum conservation for an interconnected array of channels, assuming incompressible and thermally expandable homogeneous flow. Although the formulation is homogeneous, empirical models are incorporated into the code to account for subcooled boiling and vapor/liquid slip in two-phase flow. Additional features of the VIPRE-W code include models for post-CHF fuel temperature calculations and fuel boiling duty evaluation at highly subcooled boiling conditions [3] and linkage to software libraries containing proprietary correlations and models. The new features enhance the code capability for PWR core design and licensing applications, but they do not alter the fundamental solution scheme of the VIPRE-01 code.

The VIPRE-W modeling of the test bundles is consistent with the benchmark specifications [1]. The radial geometric models are shown in Figure 2. The axial nodal length was set to be about $45.4 \mathrm{~mm}$ ( 1.8 inch). The two-phase flow model for comparison with the void data consisted of a profile fit 
TABLE 5: Initial condition of transient void tests.

\begin{tabular}{|c|c|c|c|c|c|}
\hline \multirow{2}{*}{ Test bundle } & \multicolumn{4}{|c|}{ Initial conditions } & \multirow{2}{*}{ Transients } \\
\hline & Pressure (bar) & Mass flux $\left(10^{6} \mathrm{~kg} / \mathrm{m}^{2} \mathrm{~h}\right)$ & Power $(\mathrm{kW})$ & Inlet temperature $\left({ }^{\circ} \mathrm{C}\right)$ & \\
\hline \multirow{4}{*}{ B5 } & 151.2 & 11.95 & 2282 & 300.4 & Power \\
\hline & 150.8 & 11.93 & 2244 & 301.2 & Flow \\
\hline & 150.0 & 11.92 & 2236 & 300.4 & Pressure \\
\hline & 149.6 & 11.94 & 2230 & 301.7 & Temperature \\
\hline \multirow{4}{*}{ B6 } & 155.1 & 11.55 & 2621 & 288.1 & Power \\
\hline & 155.3 & 12.03 & 2574 & 288.8 & Flow \\
\hline & 151.6 & 12.02 & 2556 & 288.2 & Pressure \\
\hline & 154.2 & 11.92 & 2603 & 288.8 & Temperature \\
\hline \multirow{4}{*}{ B7 } & 155.1 & 12.02 & 2500 & 291.9 & Power \\
\hline & 155.0 & 12.04 & 2405 & 292.0 & Flow \\
\hline & 152.0 & 11.99 & 2577 & 291.8 & Pressure \\
\hline & 155.7 & 11.99 & 2496 & 290.2 & Temperature \\
\hline
\end{tabular}

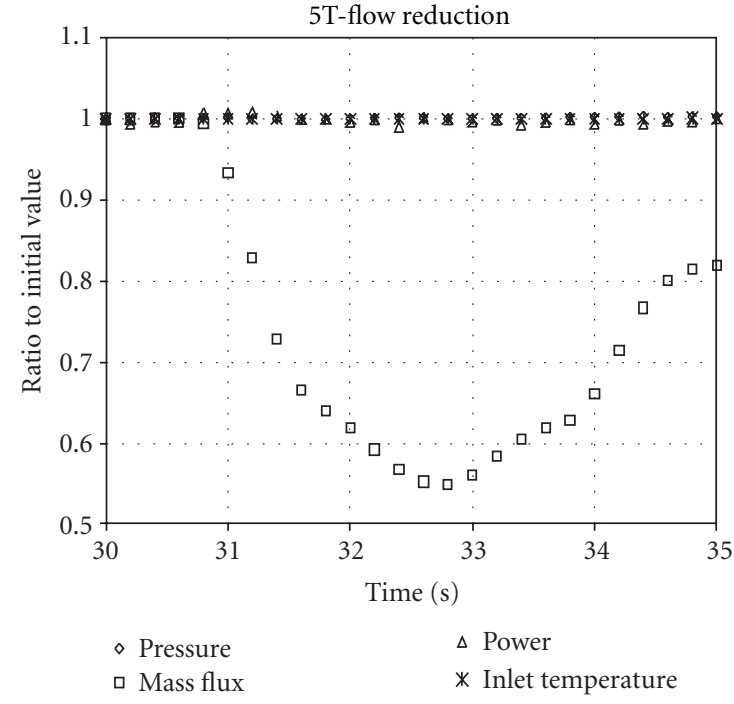

(a)

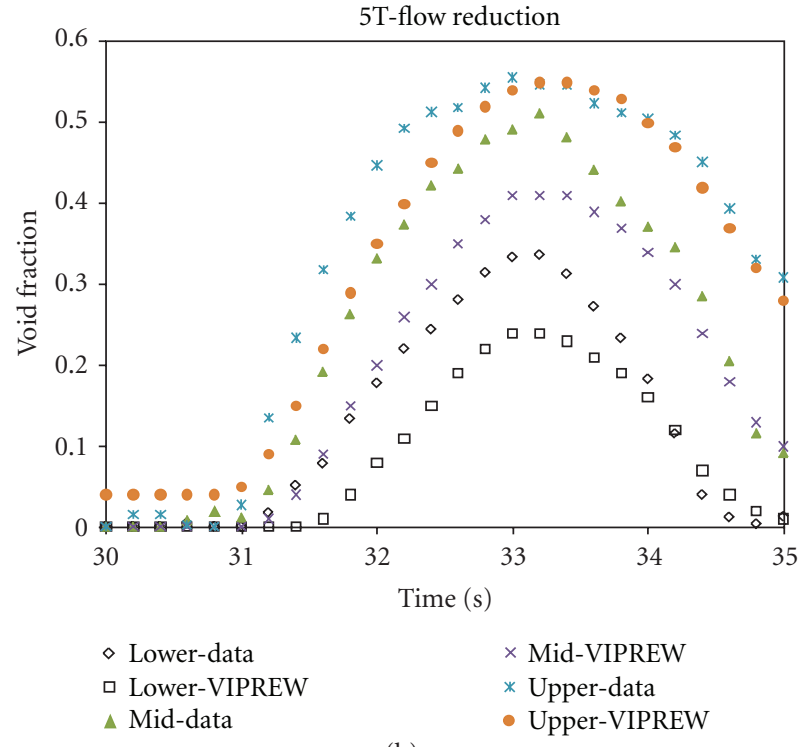

(b)

FIgURE 5: (a) B5T flow reduction (FR) transient. (b) B5T FR void comparison.

subcooled and bulk boiling model developed by Lellouche and Zolotar [4] and the associated friction multiplier also referred to as the EPRI void model [5]. It predicts the point of bubble departure from the heated surface under subcooled boiling and accounts for phase drift under bulk boiling. The EPRI void model was first selected for comparison with the PSBT data. Model sensitivity studies indicated that void predictions from other two-phase flow models in VIPRE-W were in better agreement with the test data.

The turbulent mixing in subchannels was modeled using the following empirical correlation:

$$
\Delta Q=-w^{\prime} \times \Delta h \times \Delta X,
$$

where $\Delta Q=$ energy exchange due turbulent mixing ( $\mathrm{W}$ or $\mathrm{Btu} / \mathrm{hr}), w^{\prime}=$ lateral turbulent flow per unit length $(\mathrm{kg} / \mathrm{s} / \mathrm{m}$ or lbm $/ \mathrm{hr}-\mathrm{ft}), \Delta h=$ enthalpy difference between two subchannels $(\mathrm{J} / \mathrm{kg}$ or $\mathrm{Btu} / \mathrm{lbm}), \Delta X=$ axial nodal length $(\mathrm{m}$ or $\mathrm{ft}$ )

$$
w^{\prime}=\mathrm{ABETA} \times G_{\mathrm{AVG}} \times S,
$$

where ABETA = empirical coefficient, $G_{\mathrm{AVG}}=$ average axial mass flow in the connected channels $\left(\mathrm{kg} / \mathrm{s} / \mathrm{m}^{2}\right.$ or $\left.\mathrm{lbm} / \mathrm{s} / \mathrm{ft}^{2}\right)$, $S=$ rod-to-rod gap width ( $\mathrm{m}$ or $\mathrm{ft}$ ).

ABETA is also referred to as thermal diffusion coefficient (TDC) derived from mixing test data. Previous rod-bundle mixing tests similar to the PSBT test indicated that turbulent mixing is sensitive to spacing between two MV grids [6], while effect of simple support grids could be neglected. Since turbulent mixing increases with reduced grid spacing, in the VIPRE-W model ABETA was varied axially to account for the nonuniform MV grid spacings of the rod bundle. The axially varied ABETA values were input through multipliers to a reference ABETA value as a function of the grid spacing. 


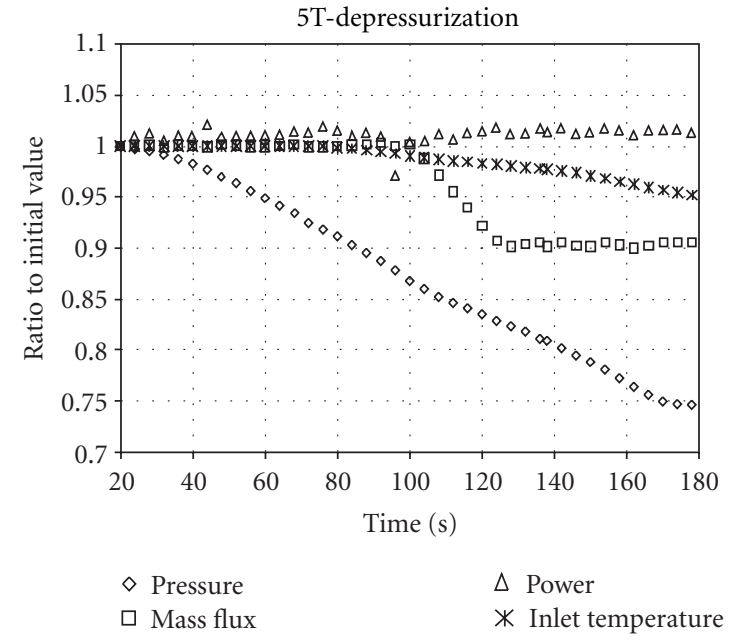

(a)

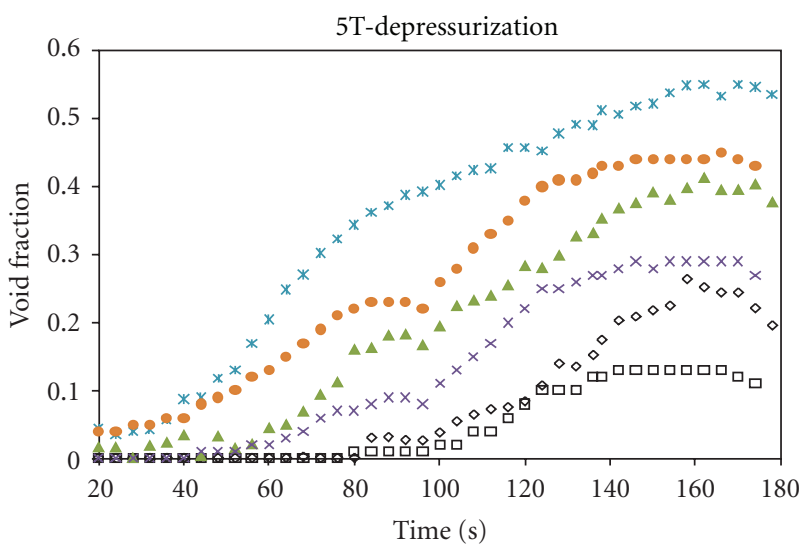

$\diamond$ Lower-data

口 Lower-VIPREW

$\triangle$ Mid-data $\times$ Mid-VIPREW
* Upper-data
- Upper-VIPREW

(b)

FIGURE 6: (a) B5T depressurization (DP) transient. (b) B5T DP void comparison.

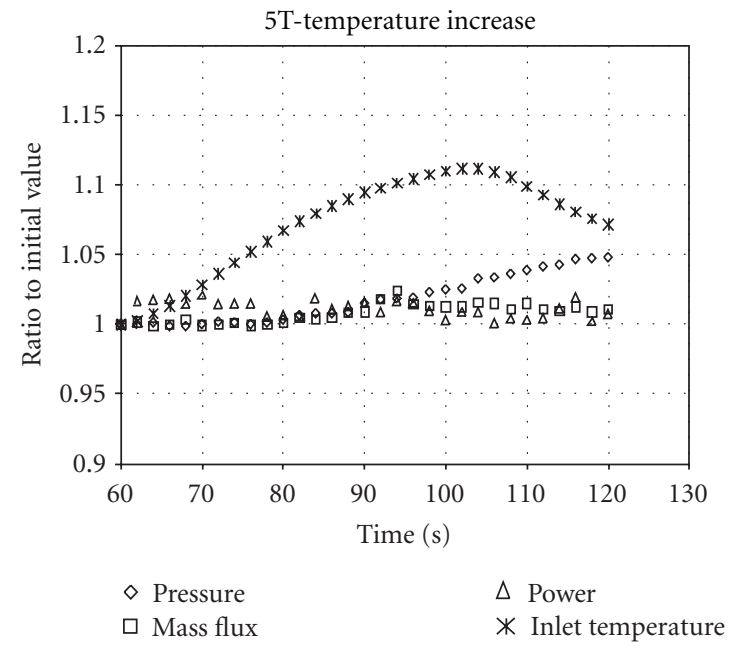

(a)

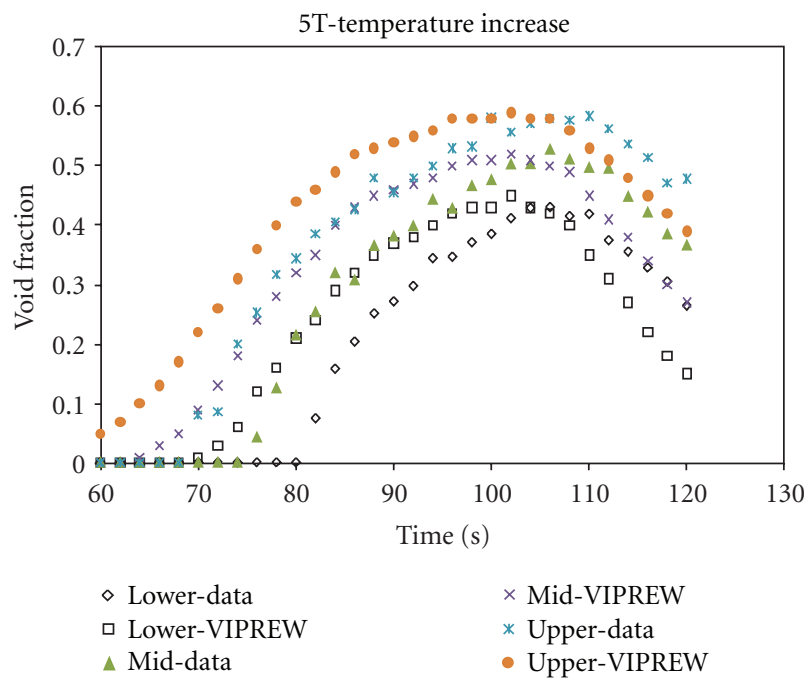

(b)

FIGURE 7: (a) B5T temperature increase (TI). (b) B5T TI void comparison.

\section{Exit Temperature Comparison}

Each datum of the mixing test (A1) contains fluid temperature measurements at the top of the heated length or the channel exit. A VIPRE-W sensitivity study was performed with different values of ABETA in (2). For each ABETA value, all test conditions are simulated yielding a set of subchannel exit temperature predictions. The predicted channel exit temperatures were then compared with the experimental data, in order to determine the best estimate reference ABETA value that yielded the smallest temperature differences. The multipliers to the reference ABETA value that varied ABETA axially as a function of the grid spacing remained unchanged during the study. A figure of merit is defined to obtain the ABETA value which gives the best overall predictions: the squared difference between measured and predicted temperature in each subchannel is averaged for each test and for each ABETA value selected in the study. The smaller the value, the better the agreement between simulation and test data. Figure 3(a) shows that the temperature differences were relatively insensitive to ABETA varied in the range from 0.055 to 0.09 . The best estimate reference ABETA value was found to be about 0.07 , corresponding to a grid spacing of $453 \mathrm{~mm}$ (17.8 inches), based on the test data from the heated rod and the grid spacer arrangements in the test bundle. As shown in Figure 3(a), the estimated ABETA values remain unchanged if only the exit temperatures of the interior channels of the test bundle were taken into consideration, excluding the peripheral channels. 


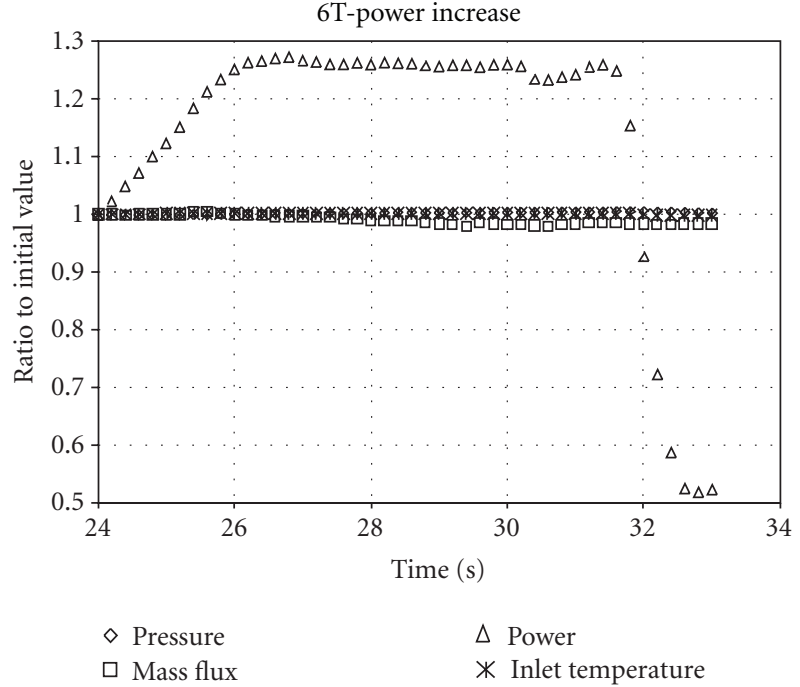

(a)

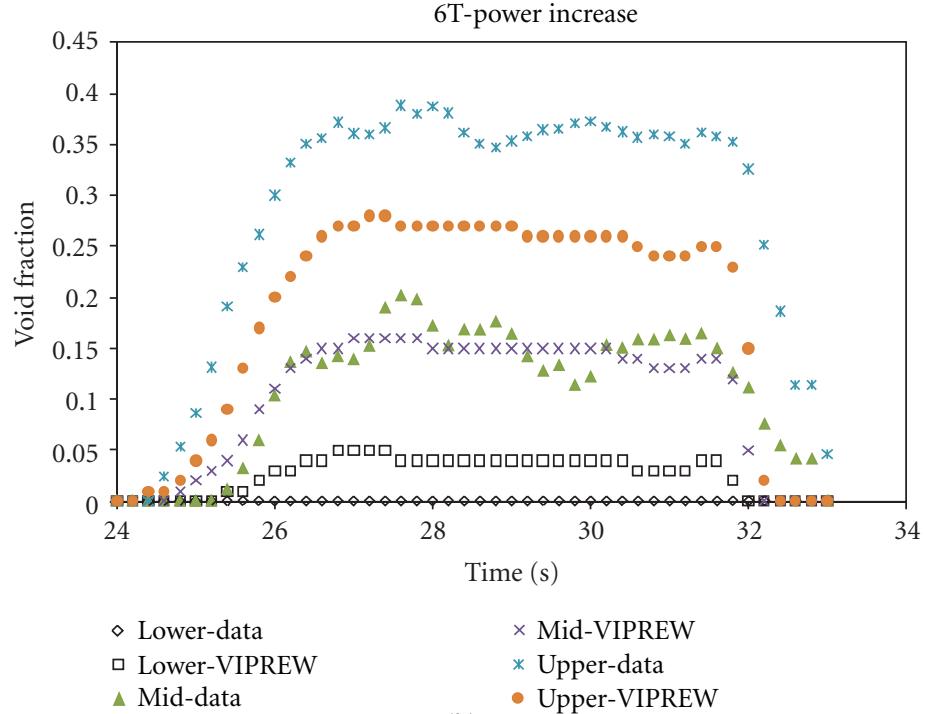

(b)

Figure 8: (a) B6T power increase (PI) transient. (b) B6T PI void comparison.

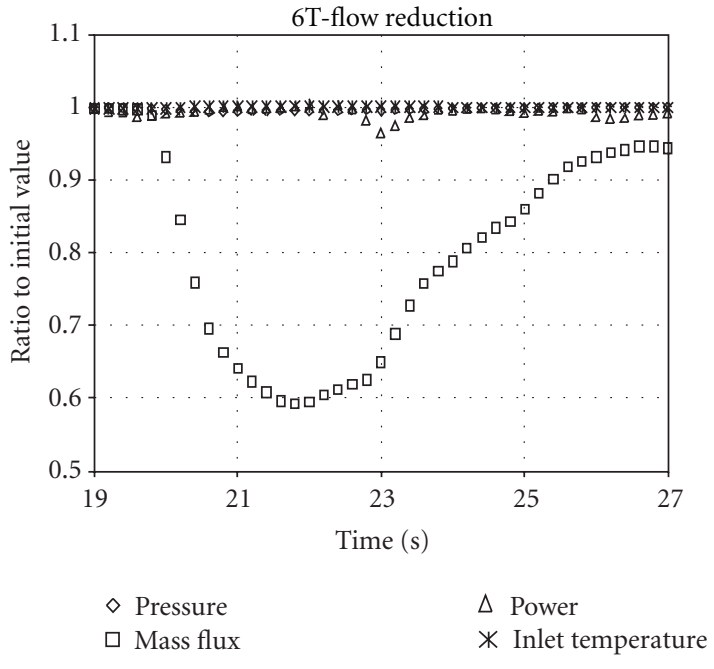

(a)

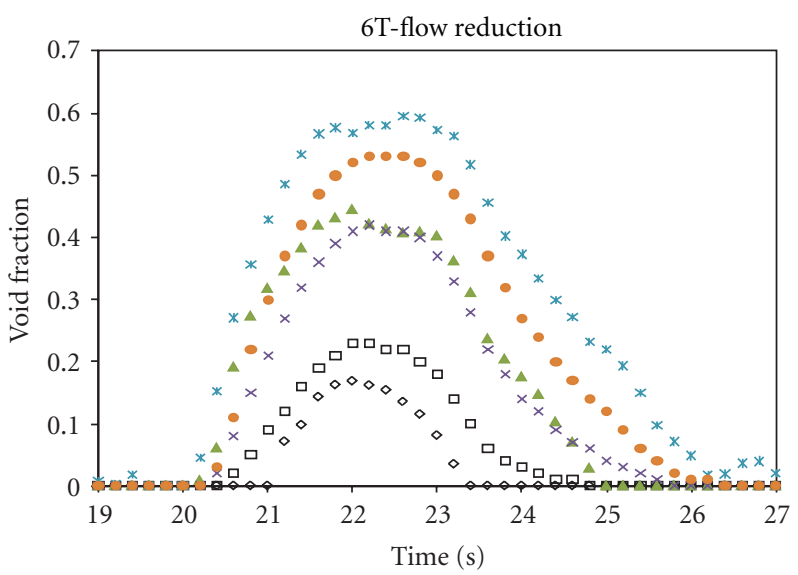

$\diamond$ Lower-data
$\square$ Lower-VIPREW
$\triangle$ Mid-data

(b)

FIGURE 9: (a) B6T flow reduction (FR) transient. (b) B6T FR void comparison.

Figure 3(b) shows the average temperature differences in each channel. The temperature differences in the rod bundle appeared to be unevenly distributed. The hot rods of the mixing test were Rod no. 1, 2, 12-18, and 22-24 in Figure 2. The measured-to-predicted temperature differences were larger in the top half of the bundle (Channels 1 through 18 in Figure 2). Despite the uncertainty in the temperature differences, the reference thermal mixing coefficient (ABETA) of 0.07 from the PSBT mixing test is consistent with those values obtained from previous mixing tests of similar configurations [6]. The ABETA values in the VIPREW model varied with axial spacings between two MV grids in the test bundle based on the predetermined function of ABETA multiplier versus grid spacing.

\section{Steady-State Void Comparison}

The predicted void fractions from the central channels of the VIPRE-W model (Channels 15, 16, 21, and 22) in Figure 2 at the three elevations, $2216 \mathrm{~mm}$ (Lower), $2669 \mathrm{~mm}$ (Middle), and $3658 \mathrm{~mm}$ (Upper), were compared with the void measurements from the three tests, $\mathrm{B} 5, \mathrm{~B} 6$, and $\mathrm{B} 7$. The comparisons based on the EPRI void model are summarized in Table 6.

There is no significant trend in the void differences with respect to the test conditions. However, the EPRI-void model tends to underpredict the void under bulk boiling at the upper elevation in comparison to the measurements. The EPRI model was modified by combining the Lellouche and 


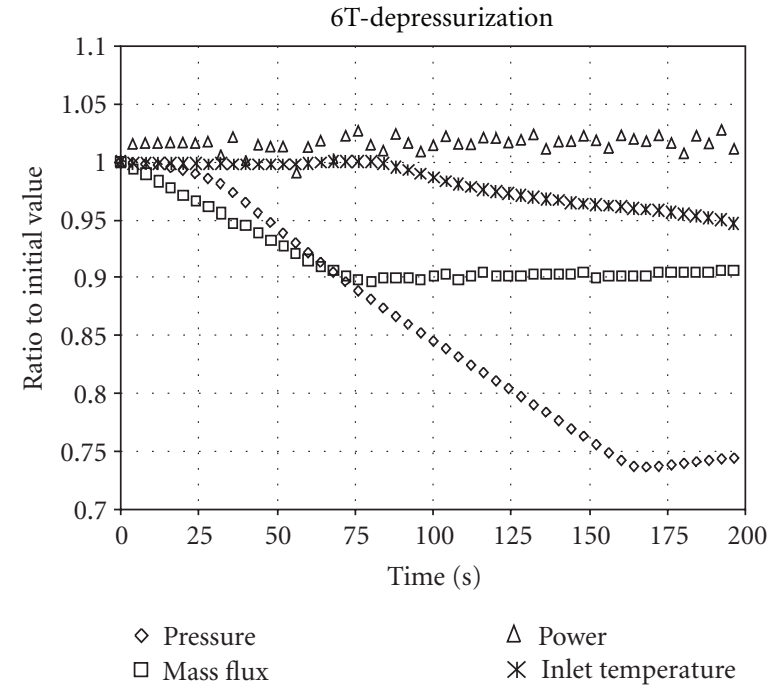

(a)

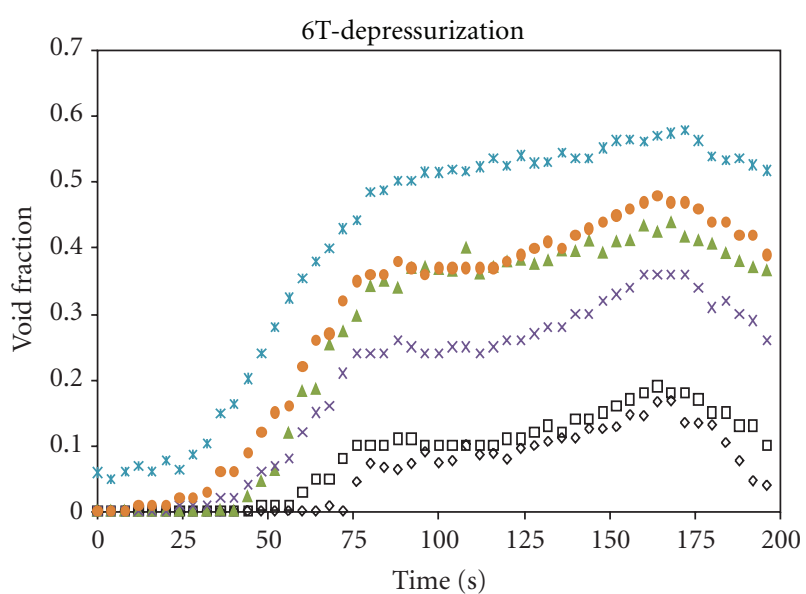

$\diamond$ Lower-data
$\square$ Lower-VIPREW
$\triangle$ Mid-data

\section{$\times$ Mid-VIPREW \\ * Upper-data \\ - Upper-VIPREW}

(b)

FIgURE 10: (a) B6T depressurization (DP) transient. (b) B6T DP void comparison.

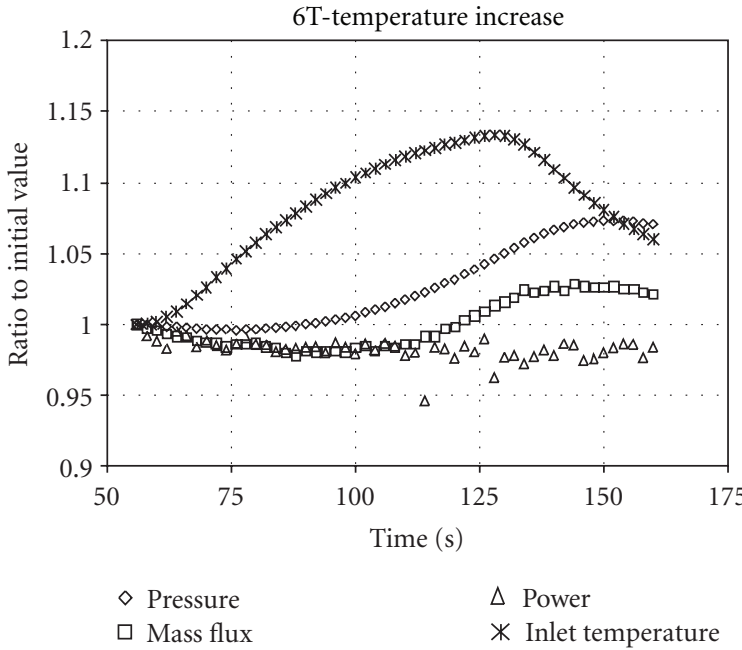

(a)

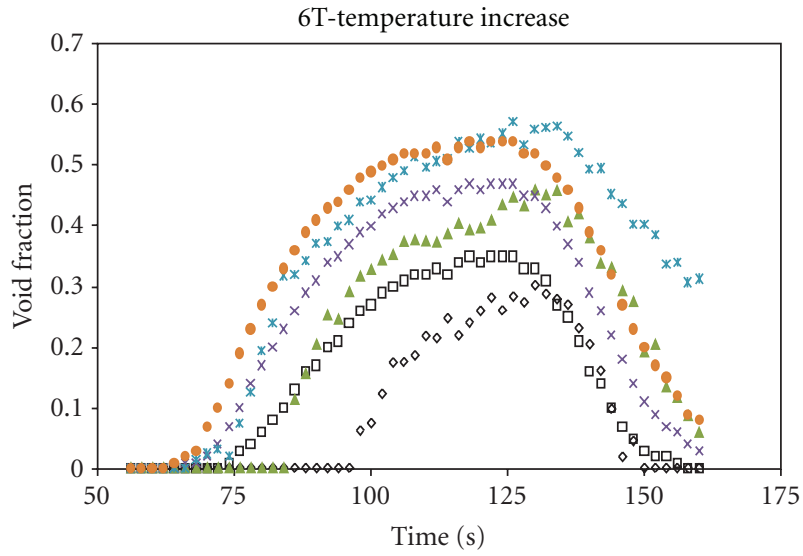

\begin{abstract}
$\diamond$ Lower-data
$\square$ Lower-VIPREW

$\triangle$ Mid-data
\end{abstract}

$\times$ Mid-VIPREW

* Upper-data

- Upper-VIPREW

(b)

FIGURE 11: (a) B6T temperature increase (TI). (b) B6T TI void comparison.

Zolotar subcooled void correlation with the homogeneous bulk boiling and two-phase flow friction multiplier. Table 7 indicates that the void predictions from the modified EPRI model are in better agreement with the data at the upper elevation.

\section{Transient Void Comparison}

The VIPRE-W time-dependent calculations were performed using the modified EPRI void model (the Lellouche and Zolotar subcooled correlation combined with the homogeneous bulk boiling and two-phase flow friction multiplier) for the power increase, flow reduction, depressurization, and temperature increase transients of the three test bundles.
The predicted void fractions from the central channels of the VIPRE-W model at the three elevations were compared with the void measurements. The comparisons are shown in Figures $4,5,6,7,8,9,10,11,12,13,14$, and 15 for the four transients of the three test bundles, B5T, B6T, and B7T. The initial condition of each transient is listed in Table 5.

The predicted time-dependent void profiles are similar to the measured values. The predicted void values are in closer agreement with the measured values from the power increase, temperature increase, and flow reduction transients than the depressurization transient. For the depressurization increase transients, the predicted values were generally lower at the upper elevation, although the magnitudes of the differences vary with the test bundles. 


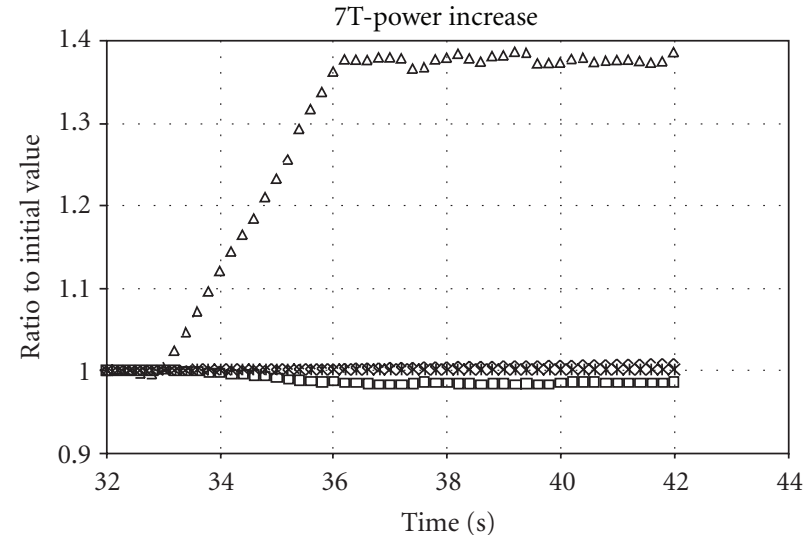

$\diamond$ Pressure $\square$ Mass flux

$$
\begin{aligned}
& \Delta \text { Power } \\
& * \text { Inlet temperature }
\end{aligned}
$$

(a)

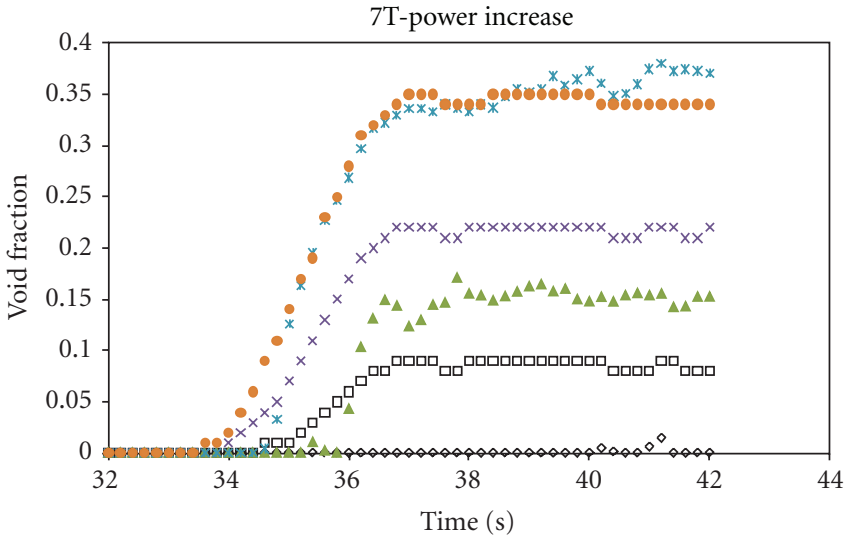

$\times$ Mid-VIPREW

* Upper-data

- Upper-VIPREW

(b)

Figure 12: (a) B7T power increase (PI) transient. (b) B7T PI void comparison.

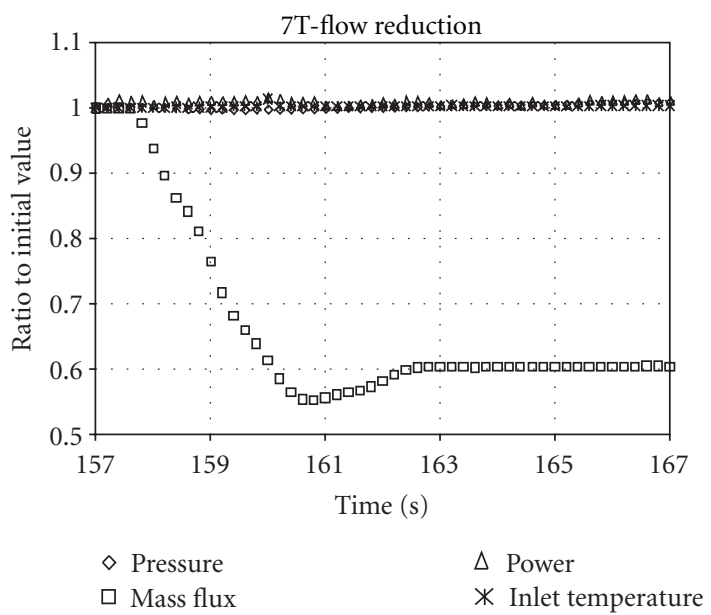

(a)

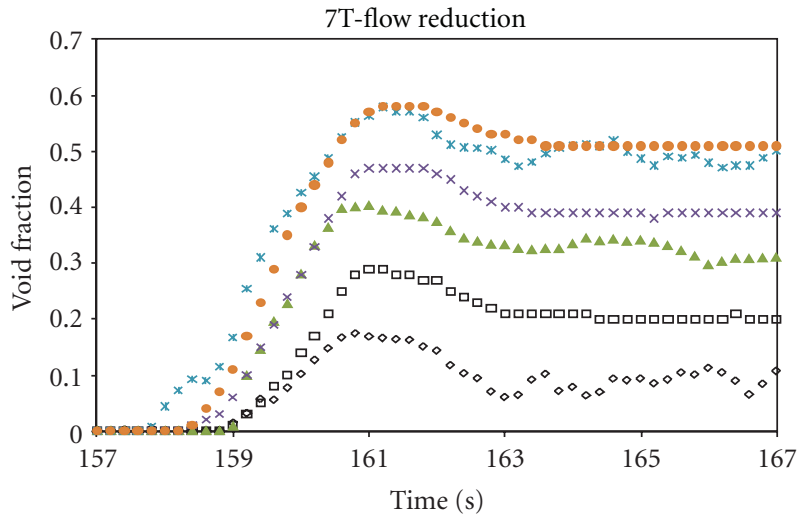

$\diamond$ Lower-data
$\square$ Lower-VIPREW
$\triangle$ Mid-data

(b) $\times$ Mid-VIPREW

* Upper-data

- Upper-VIPREW

FIgure 13: (a) B7T flow reduction (FR) transient. (b) B7T FR void comparison.

\begin{tabular}{|c|c|c|c|c|c|c|c|}
\hline \multirow{3}{*}{ Bundle test } & \multirow{3}{*}{ Number of points } & \multicolumn{6}{|c|}{ Measured-predicted void fraction } \\
\hline & & \multicolumn{3}{|c|}{ Mean } & \multicolumn{3}{|c|}{ Standard deviation } \\
\hline & & Lower & Middle & Upper & Lower & Middle & Upper \\
\hline B5 & 74 & -0.023 & -0.022 & 0.031 & 0.029 & 0.046 & 0.039 \\
\hline B6 & 74 & 0.026 & 0.051 & 0.072 & 0.049 & 0.038 & 0.044 \\
\hline B7 & 74 & -0.074 & -0.043 & 0.019 & 0.035 & 0.044 & 0.028 \\
\hline
\end{tabular}

TABLE 6: Summary of steady-state void comparison based on EPRI void model.

TABLE 7: Summary of steady-state void comparison based on modified EPRI void model.

\begin{tabular}{lcccccc}
\hline \multirow{2}{*}{ Bundle test } & & \multicolumn{3}{c}{ Measured-predicted void fraction } \\
& Number of points & & Mean & & \multicolumn{2}{c}{ Standard deviation } \\
& & Lower & Middle & Upper & Lower & Middle \\
\hline B5 & 74 & -0.025 & -0.051 & -0.018 & 0.032 & 0.058 \\
B6 & 74 & -0.029 & -0.011 & 0.021 & 0.030 & 0.038 \\
B7 & 74 & -0.081 & -0.080 & -0.032 & 0.051 & 0.054 \\
\hline
\end{tabular}




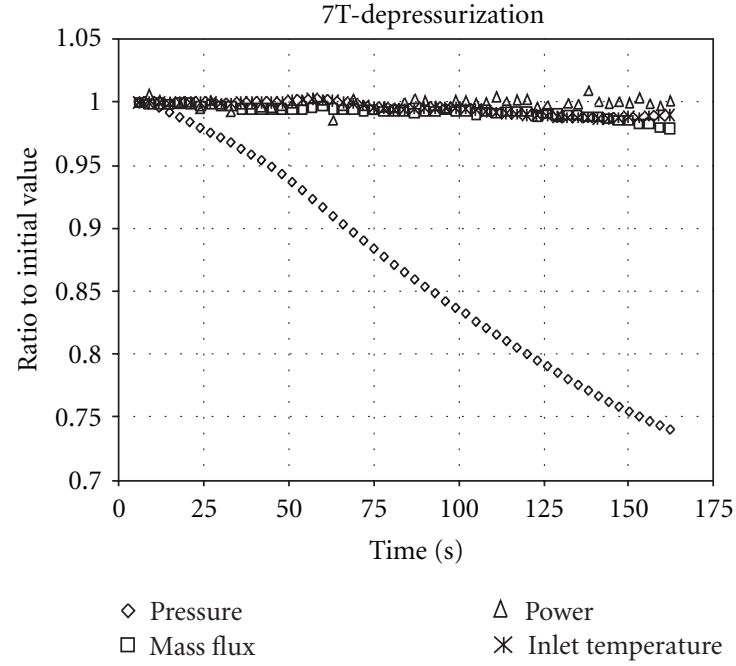

(a)

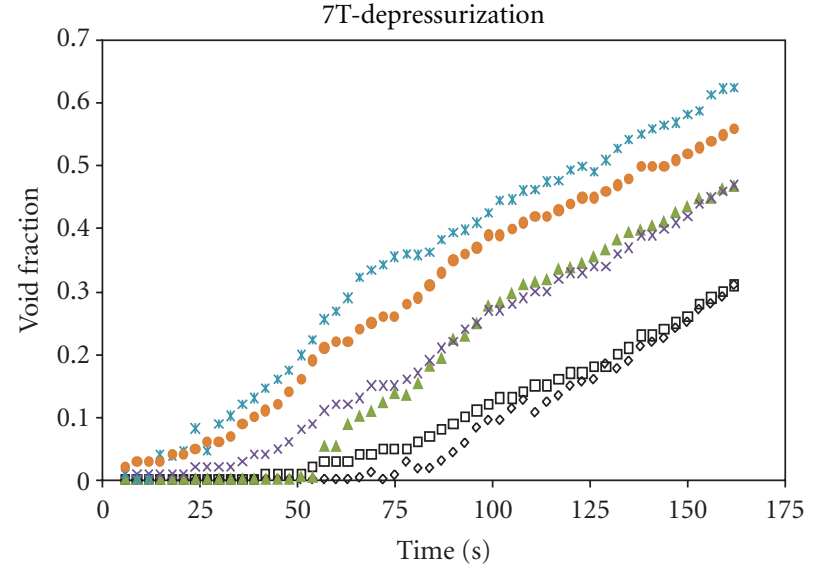

$\diamond$ Lower-data
$\square$ Lower-VIPREW
$\triangle$ Mid-data $\times$ Mid-VIPREW

* Upper-data

- Upper-VIPREW

(b)

FIGURE 14: (a) B7T depressurization (DP) transient. (b) B7T DP void comparison.

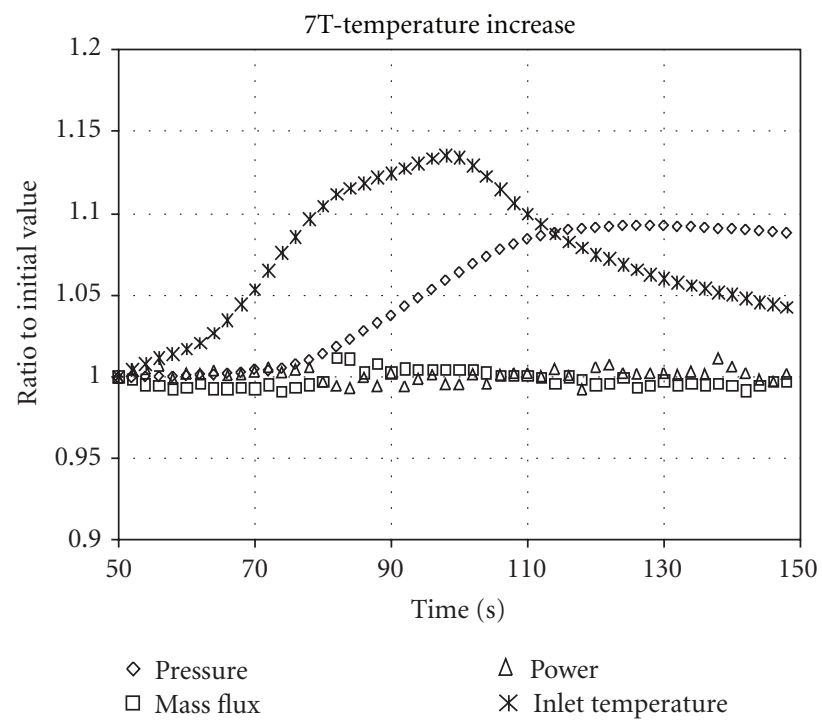

(a)

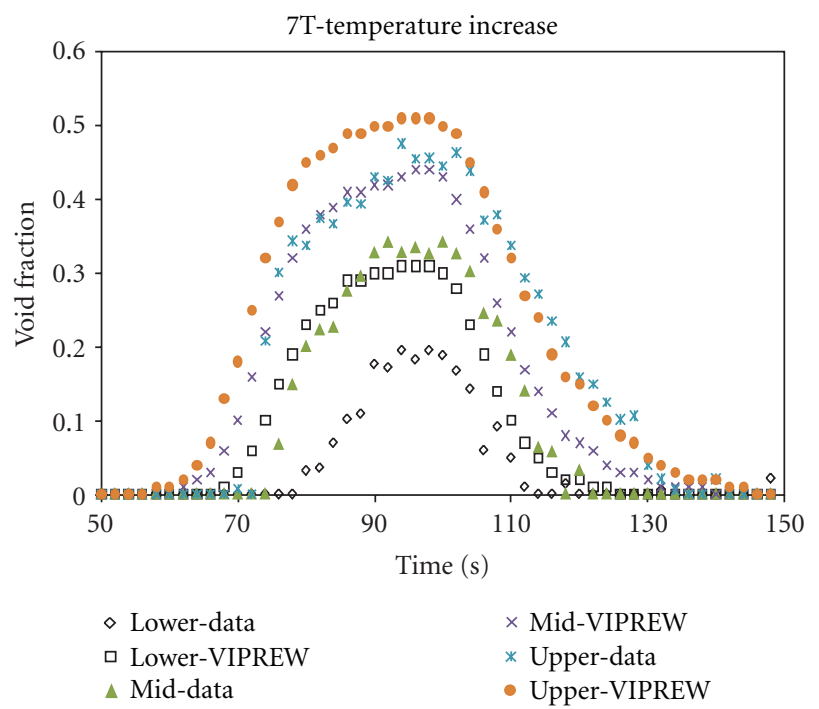

(b)

FIGURE 15: (a) B7T temperature increase (TI). (b) B7T TI void comparison.

\section{Model Sensitivity Studies}

In order to better understand the test data and to explore any improvement on code predictions, additional VIPRE-W model sensitivity studies were performed on the mixing test and the steady-state void and the transient void bundle tests.

7.1. Sensitivity Study on Mixing Test. Figure 3(b) showed that the measured-to-predicted temperature differences were larger in the top half of the rod bundle. Based on the input of the symmetric radial power distribution, VIPRE$\mathrm{W}$ predicted channel exit temperatures were also symmetric with respect to each quarter of the test bundle.
In order to understand the differences in the measured channel exit temperatures, VIPRE-W calculations were performed by varying the rod-to-wall widths up to $50 \%$, simulating a postulated symmetric loading of the test bundle in the housing. Although the changes in the bundle configuration affected the temperature distributions, there was no improvement on the comparisons between the predicted and measured temperatures at the bundle exit.

7.2. Sensitivity Studies on Void Tests. Tables 6 and 7 showed effect of different modeling options on the code predictions and the comparisons between the measured and predicted 
void fractions. Additional VIPRE-W calculations were performed by varying the turbulent momentum factor that affected momentum mixing, thermal mixing coefficient, single-phase heat transfer coefficient, local hydraulic loss coefficients, and two-phase flow models. The results of the sensitivity studies showed no significant improvement over the steady-state results in Table 7 and the transient results in Figures 4 through 15.

\section{Conclusion}

The mixing and void data from the PSBT benchmark exercises were evaluated using the VIPRE-W code. The turbulent mixing coefficient derived from code predictions in comparison to the mixing data is similar to those from previous mixing tests of similar bundle configurations. The predicted void fractions using the modified EPRI void model generally agree well with the steady-state and transient void measurements, considering uncertainties in measurements and test repeatability. The results of the sensitivity studies of different modeling options in the VIPRE-W code showed no significant improvements in the code predictions as compared to the bundle mixing and void test data.

\section{References}

[1] A. Rubin, M. Avramova, and H. Utsuno, "OECD/NRC benchmark based on NUPEC PWR subchannel and bundle tests (PSBT) volume I: experimental database and final problem specifications," Tech. Rep. NEA/NSC/DOC(2010)1, US NRC/OECD Nuclear Energy Agency.

[2] C. F. Fighetti and D. G. Reddy, "Parametric study of CHF data," Tech. Rep. NP-2609, Electric Power Research Institute, Palo Alto, Calif, USA, 1982.

[3] Y. Sung et al., "Westinghouse VIPRE-01 applications for PWR core analyses," in Proceedings of the 9th International Topical Meeting on Nuclear Reactor Thermal Hydraulics (NURETH-9), pp. 3-8, San Francisco, Calif, USA, October 1999.

[4] G. S. Lellouche and B. A. Zolotar, "Mechanistic model for predicting two-phase void fraction for water in vertical tubes, channels and rod bundles," Tech. Rep. NP-2246-SR, Electric Power Research Institute, Palo Alto, Calif, USA, 1982.

[5] C. W. Stewart et al., "VIPRE-01: a thermal-hydraulic code for reactor cores," vol. 1-3 (Revision 3, August 1989) and vol. 4 (April 1987), NP-2511-CCM-A, Electric Power Research Institute, Palo Alto, Calif, USA.

[6] F. F. Cadek, F. F. Dominicis, and D. P. Motley, "Effect of axial spacing on interchannel thermal mixing with the R mixing vane grid," Tech. Rep. WCAP-7959-A, Westinghouse Electric, 1975. 

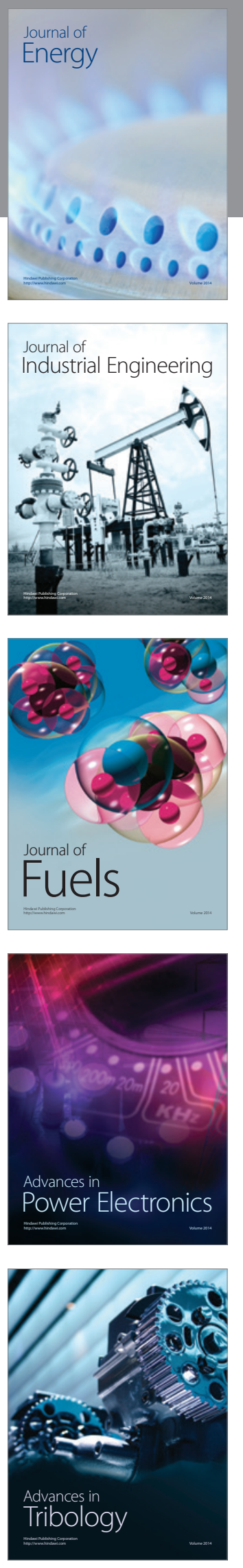
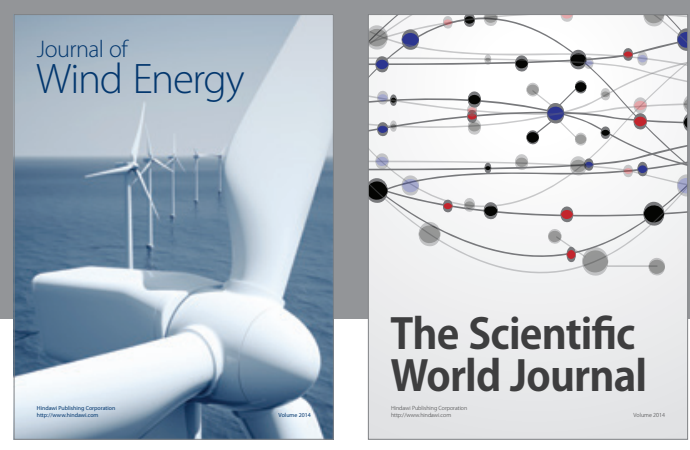

The Scientific World Journal

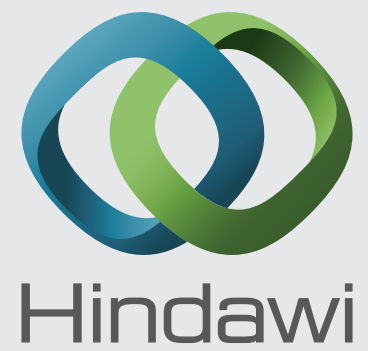

Submit your manuscripts at http://www.hindawi.com
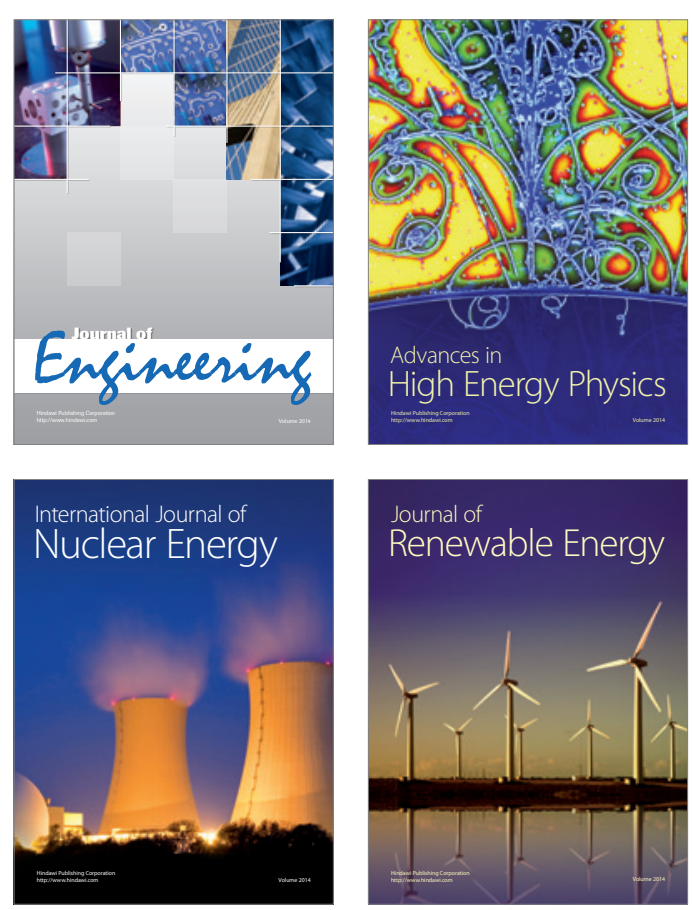

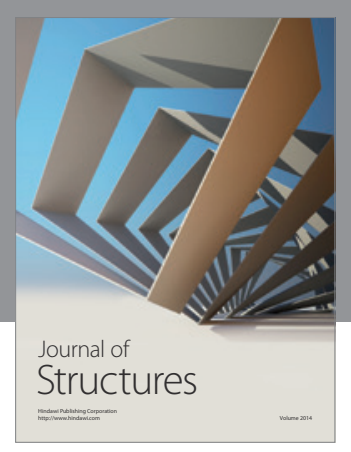

Rotating
Mechinery
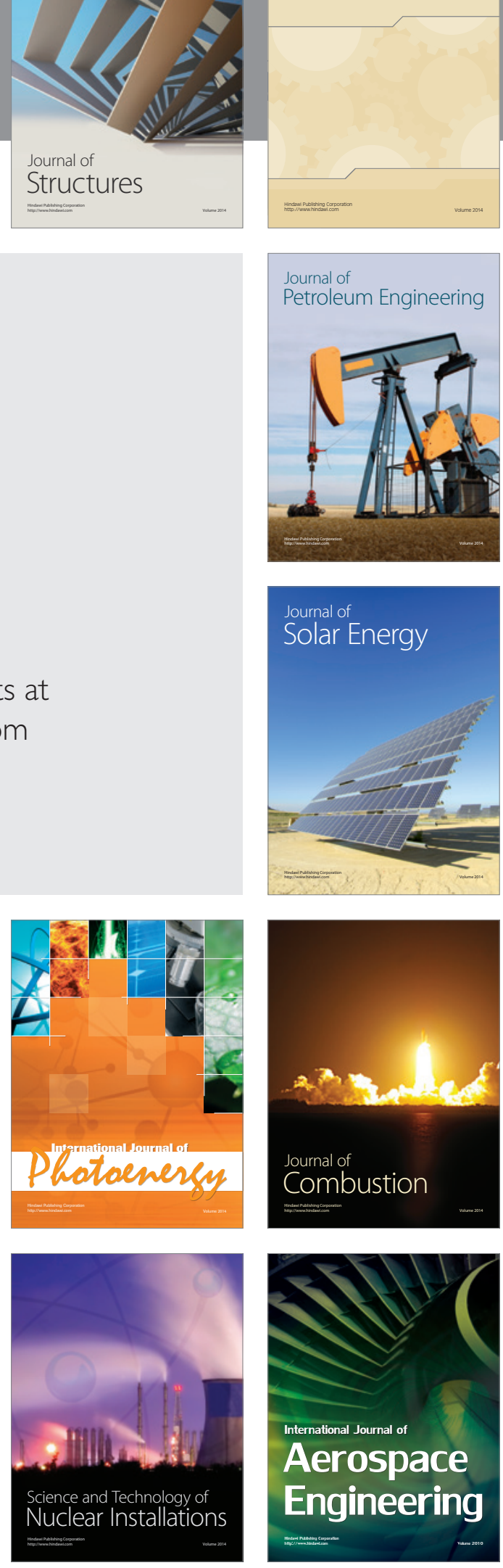